\title{
Juvenile nephronophthisis on MRI-a potential case of Joubert syndrome?
}

\author{
Roslyn J. Simms • John A. Sayer
}

Received: 10 March 2010/Accepted: 15 April 2010/Published online: 21 May 2010

(C) Springer-Verlag 2010

Sir,

We read with interest the case presentation of "End-stage juvenile nephronophthisis on MRI" [1]. We are particularly curious about the child's clinical presentation with an "abnormal gait" [1].

Nephronophthisis accounts for $6.5 \%$ of the children requiring renal replacement therapy in the United Kingdom and may be underdiagnosed [2]. As the authors acknowledge, an important feature of nephronophthisis is the association with extra-renal manifestations that can occur in up to $10 \%$ [3]. In their discussion, the authors mention Joubert syndrome, which is characterized by a midhindbrain malformation, cerebellar vermis hypoplasia and the diagnostic "molar tooth sign" on cerebral MRI [4]. We wonder whether the "abnormal gait" described in this child could be explained by Joubert syndrome and perhaps imaging with a brain MRI would be helpful?

The MRI of the kidneys clearly demonstrates the corticomedullary cysts characteristic of nephronophthisis/ medullary cystic kidney disease [1]. Diagnosis should be confirmed by molecular genetic analysis. In isolated nephronophthisis, mutations in NPHP1 account for $20-25 \%$ of cases and can be screened for by polymerase chain reaction (see http://www.orpha.net for a list of laboratories) [5]. Additionally, retinal screening for retinal dystrophy is indicated in all cases of suspected nephronophthisis.

Since nephronophthisis is an autosomal-recessive condition, with little genotype-phenotype correlation, the importance of a family history and reviewing other potentially at-risk relatives should be emphasised.

\section{References}

1. Stafrace S, Khan J (2010) End-stage juvenile nephronophthisis on MRI. Pediatr Radiol Feb 25 [Epub ahead of print]

2. Lewis M, Shaw J, Reid C et al (2007) Demography and management of childhood established renal failure in the UK (chapter 13). Nephrol Dial Transplant 22:vii165-175

3. Simms RJ, Eley L, Sayer JA (2009) Nephronophthisis. Eur J Hum Genet 17:406-416

4. Valente EM, Salpietro DC, Brancati F et al (2003) Description, nomenclature, and mapping of a novel cerebello-renal syndrome with the molar tooth malformation. Am J Hum Genet 73:663-670

5. Hildebrandt F, Zhou W (2007) Nephronophthisis-associated ciliopathies. J Am Soc Nephrol 18:1855-1871
R. J. Simms $(\bowtie) \cdot$ J. A. Sayer

Institute of Human Genetics-Nephrology,

International Centre for Life, Newcastle University,

Central Parkway,

Newcastle upon Tyne NE1 3BZ, UK

e-mail: rozsimms@doctors.org.uk 